\title{
The influence of temperature differences in moist environments on surface discharges on solid insulation
}

\author{
J. Holboell, S. Sverrisson, \\ Center for Electric Power and Energy, Department of Electrical Engineering \\ Technical University of Denmark, 2800 Lyngby, Denmark \\ Email:jh@elektro.dtu.dk
}

\begin{abstract}
The electric breakdown strength of insulating surfaces in HV systems is known to be greatly affected by moisture deposited on the surface. This has been known for decades in relation to $\mathrm{HV}$ outdoor insulation. Another application range, where breakdown voltages as a function of moisture and temperature are relevant is the offshore industry. Subsea applications of high voltages systems can mean harsh temperature conditions in connection with moist environments, such that electrical breakdown conditions in these environments need special focus.
\end{abstract}

For gas insulated systems the moisture level is normally kept at a preferred minimum to avoid accumulation of condensation on the insulating surfaces, in particular on highly stressed areas [1].

In this paper has been investigated the correlation between the electric flashover voltage of an insulating surface in moist environments and the condensation process on the insulating surface, as dependent on the dynamic moisture/temperature conditions.

Under extreme environmental conditions, rapid temperature fluctuations can occur and cause accumulation of water droplets on surfaces. A series of tests were conducted on an insulation sample in air, showing the flashover voltage as a function of the temperature difference between gas and insulating surface.

The breakdown field was, as expected, dependent on the formation of condensation on the surface. At high moisture content in the gas no relation between temperature gradient and flashover voltage was found, at moderate moisture the dependency did not give a clear picture.

\section{Introduction}

Solid insulators made of polymers are common in high voltage apparatus due to their high electrical withstand. However, as these insulators are subjected to contamination on their surfaces, the flashover voltage over these can be dramatically decreased. When apparatus is subjected to varying temperature conditions, moisture from the surrounding gas can be deposited as condensation on its surfaces [3]. Due to the high permittivity of water, the electric field over the wet insulator surface is distorted, resulting in field enhancements between the water droplets and less withstand ability [4]. Due to this effect, certain moisture limits are recommended for gas insulated systems. For example has the maintenance level of water content in SF6 apparatus been proposed with a safety margin with the dew point level of $-10^{\circ} \mathrm{C}[2]$.

Since temperature differences in moist environments are essential for the formation of condensation on insulating surfaces, the generation of these differences is a key issue when designing a suitable test setup.

In the present work, the different thermal capacitances are utilized in order to generate these differences. A high heat capacity of the test sample in connection with rapidly changing gas temperatures gives the possibility to generate temperature differences by means of a heating process, the $\mathrm{dT} / \mathrm{dt}$ of which will be decisive for the temperature difference to be achieved.

Having generated sufficient temperature differences between moist gas and insulating surface to cause the formation of condensation on the insulator surface, allows for testing of the breakdown strength of this surface as a function of the condensation formed.

Under the investigations, condensation on the surface is not measured directly, but focus is on the behaviour of the electrical breakdown strength as a function of the conditions, which will cause condensation and therefore lower withstand voltages.

The results are mainly presented as flashover voltage. In this case, this has to be understood as a measure of the breakdown strength in certain geometries under certain environmental conditions. Since the investigations mainly aim at understanding and indicative numbers in practical situations, no attempt has been made give a comprehensive picture of the electrical breakdown strength on insulating surfaces.

\section{Design considerations}

Design of a test system for flashover at insulating surfaces under moist conditions needs a number of considerations, to be taken into account to ensure well defined conditions and reproducibility of the results. 
The following aspects have to be taken into consideration:

\begin{tabular}{|c|c|}
\hline Aspect & Comments \\
\hline $\begin{array}{l}\text { Surface } \\
\text { condition }\end{array}$ & $\begin{array}{l}\text { The surface must not change under the test. } \\
\text { In the present investigations, no tracking } \\
\text { was observed after the tests. }\end{array}$ \\
\hline $\begin{array}{l}\text { Surface } \\
\text { charges }\end{array}$ & $\begin{array}{l}\text { Investigating surface discharges means } \\
\text { usually that surface charges need to be } \\
\text { taken into consideration. In this case, time } \\
\text { between the flashovers was about } 1 \text { min. } \\
\text { Taken into account the moist conditions, } \\
\text { charge decay is expected to take place in } \\
\text { much shorter time. }\end{array}$ \\
\hline $\begin{array}{l}\text { Condensation } \\
\text { on the } \\
\text { surface }\end{array}$ & $\begin{array}{l}\text { Dew point and hydrophobicity are } \\
\text { essential. Regarding the dew point, the } \\
\text { difference between surface and gas was } \\
\text { chosen such that condensation occurred. } \\
\text { Regarding hydrophobicity, this is material } \\
\text { dependent. Initial tests without voltage } \\
\text { showed that condensation took place on the } \\
\text { PMMA surface under the given conditions. }\end{array}$ \\
\hline Humidity & $\begin{array}{l}\text { Initial calibration with the test chamber } \\
\text { was conducted in order to control the } \\
\text { humidity. Alternatively, the humidity could } \\
\text { be measured inside the test chamber. }\end{array}$ \\
\hline Temperature & $\begin{array}{l}\text { Since condensation takes place as a } \\
\text { consequence of under cooling of humid air, } \\
\text { the temperature conditions in the setup are } \\
\text { important. In the investigations, cooling } \\
\text { and heating is achieved by temperature } \\
\text { control of the gas and the different thermal } \\
\text { capacities in the setup cause the necessary } \\
\text { dT/dt. }\end{array}$ \\
\hline
\end{tabular}

Table 1: Aspects to be taken into account under test system design.

\section{Experimental setup}

A cylindrical 10mm high test object of poly methyl methacrylate (PMMA) was placed in a plane parallel electrode gap with rounded edges and a diameter considerably larger than the test sample, thereby forming a homogeneous electric field around the sample.

High AC voltage was applied to the upper electrode, the lower one was grounded.

Temperature sensors were connected to the electrode as a measure of the sample temperature.

The electrode arrangement can be seen in fig. 1 .

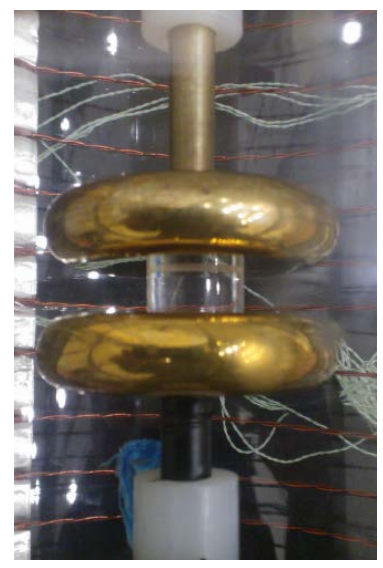

Fig. 1: $\quad$ PMMA test object between the plane parallel electrodes.

The electrode arrangement was placed in a hermetically sealed 14 litre acrylic chamber, the water content of which was observed using a hygrometer. Cooling was provided by means of controlled heat exchange with an outer chamber held constantly at a temperature of $-25^{\circ} \mathrm{C}$. A heating element wrapped around the outer surface of the chamber ensured controlled heating conditions. The chamber can be seen in fig.2.

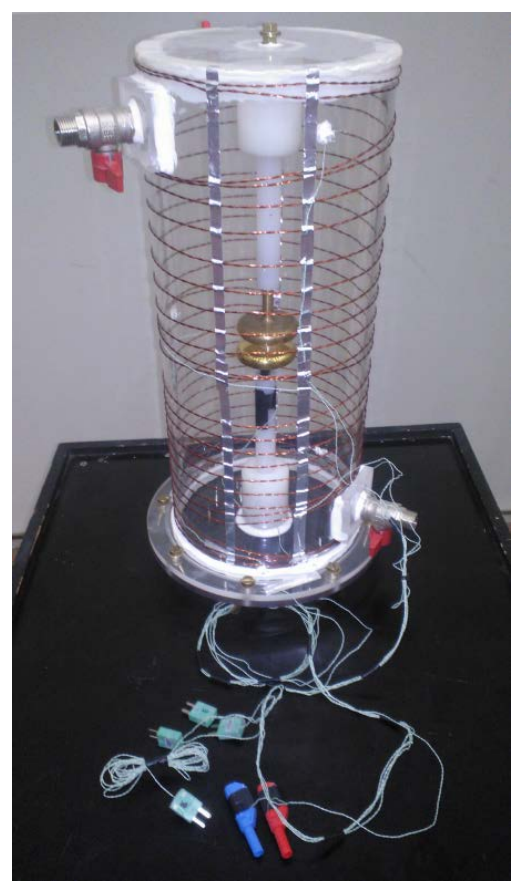

Fig. 2: Temperature and moisture controlled chamber, housing test object and electrodes. Clearly can be seen the heating wires wrapped around the chamber and the inlet and outlet for the cold gas. 
Temperature sensors were installed at different places in the test chamber:

- $\quad$ At the cooling air inlet

- $\quad$ At the chamber walls at 3 different heights

- $\quad$ In the chamber with no wall contact

- $\quad$ On the electrodes

Temperature was measured at inside the test cell and on the electrodes. Since the temperature could not be measured directly on the sample surface, a slight delay between electrode and sample surface temperature under heating and cooling can be expected. Uniform heating of the gas is ensured by placing the heating wires around the whole test chamber.

\section{Test procedure}

The flashover voltage was measured under 6 heat cycling tests causing different temperature differences between gas and sample surface. The tests were done at 2 different moisture contents in the gas.

\section{Humidity control:}

In order to control humidity, the following procedure was applied:

1. The chamber was filled with dry nitrogen.

2. Based on the chamber volume, the correct amount of water was injected into the chamber in order to achieve the 2 moisture contents:
a. $\quad 0.2 \mathrm{ml}$ water to get $14 \mathrm{ppm}$
b. $0.4 \mathrm{ml}$ water to get $29 \mathrm{ppm}$

Heat cycles:

One heat cycle is defined as:

1. The whole chamber with gas, electrodes and sample was cooled down to $-20 \mathrm{C}^{\circ}$.

2. The gas was heated from outside the chamber by means of different currents through the heating elements in order to generate different temperature differences between sample and gas.

3. When the test sample reaches $10 \mathrm{C}^{\circ}$, the temperature difference between gas and sample $\nabla \mathrm{T}$ is recorded and the high voltage tests are conducted.

\section{High voltage tests}

An increasing $50 \mathrm{~Hz}$ AC voltage is applied to the electrodes until flashover. The flashover voltage is recorded and the high voltage test is repeated several times to investigate the development of the breakdown strength.

\section{Results}

Fig. 2 shows the measured flashover voltages at each heating cycle. Looking at the first measurement in every case, it is very clear that more humid conditions generate lower flashover voltages. The first 3 subsequent flashovers occur at higher voltages, which is assumed to be due to the moisture being removed from the surface by the discharges. Further flashovers did not give a clear picture.

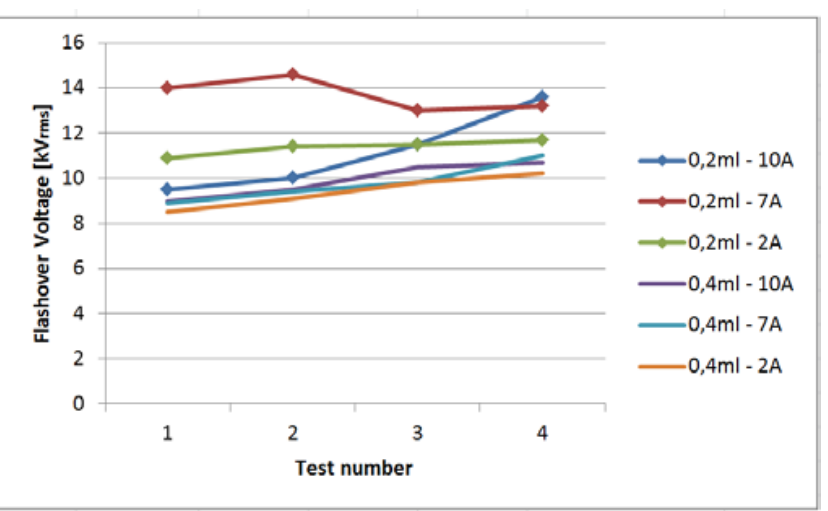

Fig. 3: Flashover voltages measured 4 times with 1 min interval for each of the 6 heat cycles.

In fig. 4 the measured flashover voltages as a function of the temperature difference between gas and sample surface $\nabla \mathrm{T}$ with 2 different moisture contents can be seen.

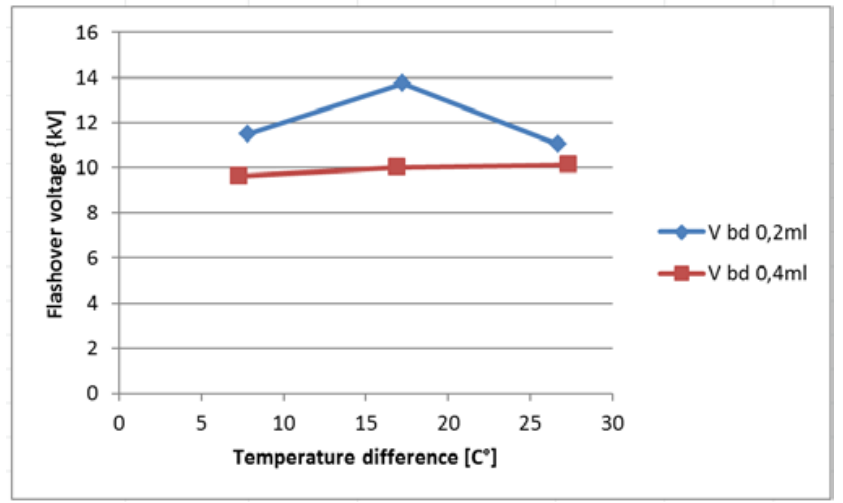

Fig. 4: Measured flashover voltages as a function of the temperature difference between gas and sample surface $\nabla \mathrm{T}$ with 2 different moisture contents. 
.The results show that:

- The highest fflashover voltage is $14 \mathrm{kV}_{\text {rms }}$, equivalent to a breakdown field strength of 1.4 $\mathrm{kV}_{\mathrm{rms}} / \mathrm{mm}$. This is below the theoretic maximum of $2.1 \mathrm{kV}_{\mathrm{rms}} / \mathrm{mm}$ in dry air, but is twice the break down field strength, measured under realistic conditions in dry air of $0.7 \mathrm{kV}_{\mathrm{rms}} / \mathrm{mm}$ [4].

- Higher moisture content in the gas generates lower flashover voltages

- $\quad$ At a high moisture content, the flashover voltages seem to be unaffected by the temperature difference between gas and sample surface $\nabla \mathrm{T}$.

- $\quad$ At lower moisture content, the flashover voltage is affected, but no clear relationship can be given.

\section{Discussion}

Formation of condensation on the sample surface affects, as expected, the electrical breakdown properties of the insulating surface,

A lower flashover voltage was observed at higher moisture content in the system. This could be expected, since the water droplets on the surface, by means of their high permittivity, generate field enhancements in between them, with lower flashover voltages as consequence.

The sequences of discharges under each test confirm that the first flashover affects the surface conditions, like evaporation of the water droplets. Subsequent flashovers consequently show different, mainly higher flashover voltages. No tracking was observed on the PMMA surface and surface charges are in these moist environments not considered as having influence.

However, the results also show a less clear picture regarding the influence of the temperature differences, as relevant for real applications, where rapid heating/cooling can appear. In order to improve the setup the following should be considered:

- $\quad$ The temperature of the sample surface is assumed to be the same as the electrodes. Direct measurement could confirm this.

- It was not possible to observe condensation on the surface, therefore the actual surface state in the different areas before, under and after the discharges is unclear. Monitoring of the surface conditions is recommended.

- Since no clear indication of the temperature difference having influence, the moisture content of the air could be varied over a larger range.

- Change of hydrophobicity of the sample surface by means of application of other materials would give a more thorough picture of the voltage/humidity/temperature relation.

\section{Conclusion}

The relation between the electric flashover voltage of an insulating surface and water condensation on the surface was investigated.

The results confirm the influence of humidity and condensation on the electrical surface breakdown strength under application of AC voltages. Higher humidity generates lower breakdown strengths.

The second focus in these investigations was on possible influence of the temperature difference between insulating surface and the surrounding moist gas. No relation could be found at $29 \mathrm{ppm}$ moisture, which might indicate that at that moisture level, the rate of temperature change is not relevant for the breakdown strength.

\section{References}

[1] IEEE Guide for Moisture Measurement and Control in SF/Sub 6/ Gas-Insulated Equipment," IEEE Std 11251993 , vol., no., $\quad$ pp.i,, 1994 doi: 10.1109/IEEESTD.1994.121445

[2] Nitta, T.; Shibuya, Y.; Fujiwara, Y.; Arahata, Y.; Takahashi, H.; Kuwahara, H., "Factors Controlling Surface Flashover in SF6 Gas Insulated Systems," Power Apparatus and Systems, IEEE Transactions on, vol.PAS97, no.3, pp.959,968, May1978B.

[3] D.Konig, "Problem der Isoliergasfeuchte in metalgekapselten Hochspannungs-Schaltanlagen", ETZA, Bd. 94, H. 7, S. 384-390, 1973.

[4] Kreuger F.H., “Industrial High Voltage”. ISBN 978-906275-561-5, Delft University Press 1991. 